\title{
ON 'THE DENIAL OF BIVALENCE IS ABSURD'1
}

\author{
Francis Jeffry Pelletier and Robert J. Stainton
}

Timothy Williamson, in various places, has put forward an argument that is supposed to show that denying bivalence is absurd. This paper is an examination of the logical force of this argument, which is found wanting.

\section{Introduction}

Let us begin with a word about what our topic is not. There is a familiar kind of argument for an epistemic view of vagueness in which one claims that denying bivalence introduces logical puzzles and complications that are not easily overcome. One then points out that, by 'going epistemic', one can preserve bivalence - and thus evade the complications. James Cargile presented an early version of this kind of argument [Cargile 1969], and Tim Williamson seemingly makes a similar point in his paper, 'Vagueness and Ignorance', when he says that 'classical logic and semantics are vastly superior to . . . alternatives in simplicity, power, past success, and integration with theories in other domains', and contends that this provides some grounds for not treating vagueness in this way [Williamson 1996: 279]. ${ }^{2}$ Obviously an argument of this kind invites a rejoinder about the puzzles and complications that the epistemic view introduces. Here are two quick examples. First, postulating, as the epistemicist does, linguistic facts no speaker of the language could possibly know, and which have no causal link to actual or possible speech behaviour, is accompanied by a litany of disadvantages - as the reader can imagine. Second, since Williamson's preferred explanation of our failure to know the exact boundary of vague predicates is precisely that speakers don't know the relevant linguistic facts - and this because they might be changing constantly, in subtle ways-we risk preserving classical logic at the cost of giving up its usefulness. If this epistemic view is correct, then for all we know, every supposedly valid argument might involve a fallacy of equivocation between what the words in the premises mean and, milliseconds later, what the (homophonous but not known-to-be synonymous) words in the conclusion mean. It looks, then, like there will be complexities whichever way one goes. In which case, whether this familiar kind of argument ends up being compelling depends very much on detailed issues concerning which complications are introduced by which logics for vagueness.

1 The authors would like to thank the members of the Ontario Area Roundtable in Philosophy of Language for a discussion that gave rise to this paper, and David Hunter, Chris Lepock, and Ernie LePore for further discussions. Thanks also to two anonymous referees for their careful and very helpful comments.

2 A similar attitude is taken in Williamson [1994] at many places, such as pp. 3ff. Williamson continues to hold this attitude, as evidenced in the many symposia on the book. 
We note this familiar kind of argument largely to put it aside. Our interest lies elsewhere, in a bracing new argument for bivalence and the epistemic view: an original and (apparently) powerful argument to the effect that such complex details needn't be used to decide the matter because the bivalent view simply scores a knockout. This latter argument, which we will call the DBA argument (for 'the Denial of Bivalence is Absurd'), 'casts doubt on the coherence' of the non-bivalent view by 'show[ing] that ... [bivalence] must not be denied' and that 'we cannot consistently deny its [a vague sentence's] bivalence' [Williamson 1996: 265, 266, 268]. ${ }^{4}$ The argument runs as follows. To give up bivalence is, at a minimum, to assert of some sentence ' $\mathrm{P}$ ' that neither it nor its negation is true. Hence if we give up bivalence, then we have the following situation for at least one sentence ' $\mathrm{P}$ '-where (1) is the statement to be shown absurd:

(1) $\sim\left[\mathrm{T}\left({ }^{\prime} \mathrm{P} \text { ') } \vee \mathrm{T}\left({ }^{\circ} \sim \mathrm{P} '\right)\right]^{5}\right.$

(2a) $\mathrm{T}\left({ }^{\prime} \mathrm{P}\right.$ ') $\leftrightarrow \mathrm{P}$

(2b) $\mathrm{T}\left({ }^{\circ} \sim \mathrm{P} ’\right) \leftrightarrow \sim \mathrm{P}$

(3) $\sim[\mathrm{P} \vee \sim \mathrm{P}]$

(4) $\sim \mathrm{P} \& \sim P$

To make things perfectly explicit, (2a) and (2b) are supposed to be instances of Tarski's disquotational schema for truth. (3) is supposed to follow from (1) by substituting the right-hand sides of $(2 a) /(2 b)$ for their left-hand sides as they appear in (1). (4), in turn, is to follow from (3) by one of De Morgan's laws.

Now (4), it might be said, is a contradiction. Indeed, it is a contradiction even in intuitionistic logic. This, it seems, reduces (1) to absurdity even for the intuitionist. Hence, runs DBA, (1), the assertion of some sentence that it violates bivalence, is incoherent, and the denial of bivalence is thus shown to be absurd. QED.

Our concern in the present paper is with this last point, whether this argument shows that denying bivalence is absurd. We will argue that the above argument does not show that the denial of bivalence is out-and-out absurd. Denying bivalence is sure to be tricky and complicated, but, we insist, it isn't incoherent.

\section{Two Objections to DBA}

What might an advocate of non-bivalence (a 'multivalentist') say in the face of the DBA argument? Well, first the advocate might say that (4) doesn't bother them. After all, she might point out, if one denies the principle that for every sentence either it or its negation is true, then one will also claim that any such sentence will of course violate the so-called

3 The DBA argument that follows is frrom Williamson [1996: 265]; a slightly different formulation of the DBA argument is in [Williamson 1994: 188ff].

4 An identical quote to the last is on ibid. [269]. Analogues of the quotations can be found in Williamson [1994: 188ff] as well. Williamson also continues to hold this attitude as well, as evidenced, once again, in the many symposia on the book.

5 A word about our notation. Following $A J P$ 's style, we use single quotes for everything other than quotes within quotes. (This convention is also applied to cited material and our discussions of such cited material.) 
law of non-contradiction in the form $\sim(\mathrm{P} \& \sim \mathrm{P}){ }^{6}{ }^{6}$ The advocate might also point out that, as one who denies bivalence, she is not obliged to think that De Morgan's laws — or at least that particular one of the laws that is used in the above argument - apply to a logic with a third value, and so it is also not necessary to admit that (3) implies (4). We will put these considerations aside, so as to concentrate, in what follows, on two more central objections.

First, however, a word about terminology. The standard notion of 'bivalence' is that there are two truth-values, $\mathrm{T}$ and $\mathrm{F}$, and that each sentence has exactly one of these values. So, one can deny bivalence either by postulating more than two truth values, or by allowing some sentences not to have a truth-value; or again, one could allow some sentences to take more than one truth-value. In some people's terminology, it is only the first of these three that is correctly called 'multivalent'; the second type should be called 'truth-value gap' theories and the third should be called 'truth-value glut' theories. Although this paper uses the language of 'multivalence', and talks about a 'third (or more) truth value', much of what we say carries over to the gap and glut theories as well, especially in our discussion of choice vs. exclusion negation in our first objection and in our discussion of the Tarski schemas in our second objection. So far as formal issues in the DBA argument go, gap and glut theorists would make the same objections as a multivalentist; and so we shall not further remark on the differences that separate gap and glut theories from (three-valued) multivalent theories. ${ }^{7}$ In what follows, then, we talk of denying bivalence as being a matter of postulating more truth values and do not further mention gap and glut theories.

\section{A. Objection 1: Senses of Bivalence: Against $\sim\left[T\left({ }^{\prime} P\right.\right.$ ') $\left.\vee T\left({ }^{\prime} \sim P '\right)\right]$}

The first of our objections to the absurdity claim starts by pointing out that 'bivalence' has (at least) two quite different senses, and so as a corollary there are (at least) two different meanings for 'non-bivalence'. One is the standard meaning of 'bivalence' we mentioned just above: that there are only two truth-values, $\mathrm{T}$ and $\mathrm{F}$, and that each sentence has exactly one of these values. In this standard sense a non-bivalent logic would have more than two truth values (modulo gap and glut theories, as just noted). But the sense of 'bivalence' (and 'non-bivalence') being employed in the DBA is different. In the DBA argument 'bivalence' means that for each sentence, either it or its negation is $\mathrm{T}$, as shown by (1), and denying bivalence is taken to be denying that either ' $\mathrm{P}$ ' or its negation is true. It can be seen that this latter doctrine is different from the standard meaning by noting that if the negation of a sentence amounted to saying that the unnegated sentence took some value other than T, i.e., if the negation operator merely excluded the case where the unnegated sentence was true, and had this truth table (where we use $\neg$ for this 'exclusion negation')

6 There are other possible forms of 'the law of non-contradiction', such as $\sim\left(\mathrm{T}\left({ }^{\prime} \mathrm{P}\right.\right.$ ')\& $\mathrm{T}\left({ }^{\prime} \mathrm{P}\right.$ ')) or $\sim\left(\mathrm{T}\left({ }^{\prime} \mathrm{P}\right.\right.$ ') \&F('P')), that the multivalentist would not deny. But these other metalinguistic claims are not what the DBA is talking about.

7 In the discussions below, one might imagine a gap theorist replacing the I-value by 'has no truth value' and a glut theorist replacing it by 'is both true and false'. We think these two theories can and would object to the DBA in just the same ways and for the same reasons as our multi-valentists do. Of course, there is more to a gap or a glut theory than just the formal considerations we mention below. And it is true that such theories might have further resources they could employ in disputing the DBA. But we will not consider these further features. 


\begin{tabular}{c|c}
$\mathrm{P}$ & $\neg \mathrm{P}$ \\
\hline $\mathrm{T}$ & $\mathrm{F}$ \\
$\mathrm{I}$ & $\mathrm{T}$ \\
$\mathrm{F}$ & $\mathrm{T}$
\end{tabular}

Truth Table 1: An 'Exclusion Negation'

then such a three-valued logic would not be bivalent in the first sense but it would be bivalent in the second sense. The first sense of 'non-bivalence' is weaker than the second. Everyone who denies bivalence denies that there are just two truth values, ${ }^{8}$ but need not deny that for every sentence either it or its negation is true. This observation concerning senses of 'bivalence' strikes at the very heart of the DBA argument and has ramifications for almost every detail in that argument.

Recall that the entire point of the DBA argument is to show that (1) is absurd. But if a multivalentist is not committed to (1) in the first place then the rest of the argument is impotent. And the multivalentist who adopts the exclusion negation of Truth Table 1 is not committed to (1). Indeed, when the interpretation of $\vee$ is 'standard'-takes on the value of the 'most true' disjunct - then the negation of (1) is a logical truth (always has value T) in this logic. This can be seen from the following considerations. An arbitrary formula $\mathrm{P}$ of this logic can take on one of the three values: T, I, F. If it takes the value T, then $T\left({ }^{\prime} \mathrm{P}\right.$ ') is true and hence $\left[\mathrm{T}\left({ }^{\prime} \mathrm{P}\right.\right.$ ') $\vee \mathrm{T}\left({ }^{`} \neg \mathrm{P}\right.$ ') $]$ is true. If on the other hand $\mathrm{P}$ takes on one of the other two values, then $\neg \mathrm{P}$ has the value $T$, and therefore $T\left({ }^{\prime} \neg \mathrm{P}\right.$ ') is true and hence $\left[\mathrm{T}\left({ }^{\prime} \mathrm{P} '\right) \vee \mathrm{T}\left({ }^{`} \neg \mathrm{P}^{\prime}\right)\right]$ is true. So this multivalued logic in fact denies (1), and the rest of the argument is beside the point. It only gains any purchase at all by using the second, nonstandard, definition of 'bivalence' and 'non-bivalence'.

The above consideration shows that the DBA argument has no force against deniers of bivalence because it makes the false assumption that multivalentists must claim (1). Despite this we might wonder whether such logics are nonetheless committed to (3) and (4) in the argument - which after all are what is seen as objectionable. The answer is that the logic with exclusion negation makes both of (3) and (4) logically false (always take the value F) if the $\vee$ and $\&$ are 'standard', i.e., $\vee$ takes the value of the 'most true' disjunct and $\&$ takes the value of the 'least true' conjunct. Furthermore, such a logic will reject (2a) unless $\leftrightarrow$ is given a non-standard interpretation.

Let us start with (3). Mirroring the metalinguistic argument given just above about (1), we can say: either $\mathrm{P}$ has the value $\mathrm{T}$ or it takes one of the other values. If it has the value $\mathrm{T}$ then (with the standard $\vee)(P \vee \neg P)$ has the value $T$. If it has one of the other values then $\neg \mathrm{P}$ has the value $T$ and therefore $(\mathrm{P} \vee \neg \mathrm{P})$ has the value $\mathrm{T}$. So in any case $(\mathrm{P} \vee \neg \mathrm{P})$ has the value $\mathrm{T}$ and is therefore a logical truth of this logic. It follows that (3) in the DBA argument, viz. $\neg(\mathrm{P} \vee \neg \mathrm{P})$, is always $\mathrm{F}$ in this logic, and so the logic does not contain this allegedly objectionable consequence. Consider now (4) of the DBA argument. Once again P takes exactly one of the three values. If $\mathrm{P}$ has the value $\mathrm{T}$ then $\neg \mathrm{P}$ has the value $\mathrm{F}$, and hence $(\neg \mathrm{P} \& \neg \neg \mathrm{P})$ will have the value $\mathrm{F}$ (with \& being a standard conjunction). If $\mathrm{P}$ takes one of the other two values, then $\neg \mathrm{P}$ has the value $\mathrm{T}$ and $\neg \neg \mathrm{P}$ has the value $\mathrm{F}$; and so ( $\neg \mathrm{P} \& \neg \neg \mathrm{P}$ ) has the 
value F. Therefore (4) of the DBA argument, like (3), is logically false in this logic. So the multivalentist, choosing the right logic, won't be committed to either of the objectionable conclusions. (Of course, a slightly different statement, $(\mathrm{P} \& \neg \mathrm{P})$, is not logically false for the careful multivalentist. For, if $\mathrm{P}$ has the value $\mathrm{I}$ then $\neg \mathrm{P}$ has the value $\mathrm{T}$, and therefore $(\mathrm{P} \& \neg \mathrm{P})$ has the value I. So some 'contradictions' do not always take the value F. But the one in the DBA argument is always $\mathrm{F}$ in this logic. $)^{9}$

Finally, let us look at how the disquotational principles are handled in this logic. A 'standard biconditional' (Williamson's 'strong reading of the biconditional' [1996: 267]) makes a biconditional $\mathrm{T}$ if each side has the same value and false if the sides have different values. A 'semi-standard biconditional' relaxes this condition so that a biconditional is $\mathrm{T}$ when each side has the same value, and it is false if each side has different classical values (they differ but each have a $\mathrm{T}$ or $\mathrm{F}$ value). They take the value I when one side is classical and the other is I. Let us consider a truth table for (2a) and (2b), using our exclusion negation, ᄀ:

\begin{tabular}{|c|c|c|c|c|c|}
\hline & & & & $(2 a)$ & $(2 b)$ \\
\hline $\mathrm{P}$ & $\neg \mathrm{P}$ & $\mathrm{T}\left({ }^{\prime} \mathrm{P} '\right)$ & $\mathrm{T}\left({ }^{\prime} \neg \mathrm{P}^{\prime}\right)$ & $\mathrm{T}\left({ }^{\prime} \mathrm{P} '\right) \leftrightarrow \mathrm{P}$ & $\mathrm{T}\left({ }^{\prime} \neg \mathrm{P}^{\prime}\right) \leftrightarrow \neg \mathrm{P}$ \\
\hline $\mathrm{T}$ & $\mathrm{F}$ & $\mathrm{T}$ & $\mathrm{F}$ & $\mathrm{T}$ & $\mathrm{T}$ \\
\hline I & $\mathrm{T}$ & $\mathrm{F}$ & $\mathrm{T}$ & $? ?$ & $\mathrm{~T}$ \\
\hline $\mathrm{F}$ & $\mathrm{T}$ & $\mathrm{F}$ & $\mathrm{T}$ & $\mathrm{T}$ & $\mathrm{T}$ \\
\hline
\end{tabular}

Truth Table 2: Truth Tables for Disquotational Principles.

One notes that in the middle row of the (2a) column the two sides of the biconditional have different truth values: one side has the value $\mathrm{F}$ while the other side has the value I. If $\leftrightarrow$ were a standard biconditional, then there would be an F in this location, and if $\leftrightarrow$ is a semi-standard biconditional it would have an I in this location. ${ }^{10}$ In either case it means that (2a) is not a logical truth for this logic since it does not always take the value T. (We will see below in the second objection to the DBA argument that disagreements over the (2a) and (2b) disquotational schemas are not restricted to considerations of exclusion negation but form part of a more pervasive feature of multivalent logics.)

One final remark, before we leave the issue of what 'bivalence' must mean. It seems to us that Williamson's selection of the non-standard notion of bivalence to focus upon is due to his antecedent commitment to an epistemic account of vagueness. He thinks of reality as a matter of possession or absence of a property: one is either thin or not, bald or not, etc. Given such a point of view, it might seem that if there is no ontological vagueness, then either 'TW is thin' is true or 'TW is not thin' is true. But if this is why he focuses on the non-standard (1), then the DBA can't be used to support an epistemic account of vagueness. Rather, it simply begs the question against ontological accounts.

9 And although we said earlier that we would not any further consider the status of the DeMorgan Laws, we nonetheless will point out that $\neg(\mathrm{P} \vee \mathrm{Q})$ and $(\neg \mathrm{P} \& \neg \mathrm{Q})$ are equivalent in this logic —as a simple truth table will show.

10 The same issue does not arise with the (2b) biconditional, since both sides have classical truth values. 


\section{B. Objection 2: Disquotational Schemas: Against $\left[P \rightarrow T\left({ }^{\prime}\right)\right]$}

The preceding 'first objection' to the DBA argument pointed out that the disquotational schemas are not logical truths, since the negation in question might have been an 'exclusion negation' of the sort defined in Truth Table 1. But, as hinted above, the proponent of DBA no doubt has in mind that the multivalentist who is interested in vagueness will employ a 'choice negation' account of negation like the following, where the negation of an indeterminate value is itself indeterminate. We use ' $\sim$ ' as our symbol for choice negation.

\begin{tabular}{c|c}
$\mathrm{P}$ & $\sim \mathrm{P}$ \\
\hline $\mathrm{T}$ & $\mathrm{F}$ \\
$\mathrm{I}$ & $\mathrm{I}$ \\
$\mathrm{F}$ & $\mathrm{T}$
\end{tabular}

Truth Table 3: A 'Choice Negation’

The second objection to the DBA argument starts, not from an abstract consideration of what bivalence is, but rather directly from the 'Tarski disquotational schemas', (2a) and (2b), and embraces the choice negation of Truth Table 3. According to the second objection, in an important sense (2a) and (2b) already presuppose bivalence, and so they are not the appropriate disquotational schemas for a multivalued logic. If a sentence ' $\mathrm{P}$ ' is true if and only if $\mathrm{P}$, and if $\mathrm{P}$ and $\sim \mathrm{P}$ always have the same truth value, ${ }^{11}$ then of course there is bivalence. No other part of the argument is necessary, including the extra fillip of intuitionist considerations. So, it is exactly towards a consideration of (2a) and (2b) that the second objection is directed.

What can be said then? It seems pretty clear that even a multivalentist will admit one direction of the disquotational schemas when $\sim$ is a choice negation:

$\left.\left(2 \mathrm{a}^{*}\right) \quad \mathrm{T}\left({ }^{\prime} \mathrm{P}\right)\right) \rightarrow \mathrm{P}$

$\left(2 b^{*}\right) \quad \mathrm{T}\left({ }^{\circ} \sim \mathrm{P}\right.$ ') $\rightarrow \sim \mathrm{P}$

['If a sentence really is true, then what it says must "obtain".'] The reason a multivalentist adopts $\left(2 \mathrm{a}^{*}\right)$ is as follows. T('P') is either true or false. ${ }^{12}$ If it is false, then the antecedent of $\left(2 \mathrm{a}^{*}\right)$ is false and the $\left(2 \mathrm{a}^{*}\right)$ claim (using classical $\rightarrow$ ) is true; if on the other hand $\mathrm{T}\left({ }^{\prime} \mathrm{P}\right.$ ') is true, then since the only time this happens is when ' $\mathrm{P}$ ' determinately has the value $\mathrm{T}, \mathrm{P}$ must indeed be the case. Hence ( $\left.2 \mathrm{a}^{*}\right)$ is true. A similar argument holds for $\left(2 \mathrm{~b}^{*}\right) .{ }^{13}$ But the other directions of the disquotational schemas are a different matter altogether. Both of

11 The exclusion negation, $\neg$, does not obey this last claim, about the equivalence of double-negations.

12 Since every formula takes exactly one of the three values, the metalinguistic operators $\mathrm{T}(x), \mathrm{F}(x)$, and $\mathrm{I}(x)$ must themselves be two-valued. The formula designated by $x$ either has the semantic value T or it doesn't; it either has the semantic value F or it doesn't; it either has the semantic value I or it doesn't. So $\mathrm{T}(x), \mathrm{F}(x)$, and $\mathrm{I}(x)$ are themselves either true or false, and not both.

13 Actually, with a choice negation, $\left(2 b^{*}\right)$ is merely that special case of $\left(2 a^{*}\right)$ where $\sim \mathrm{P}$ is substituted for the variable $\mathrm{P}$, and requires no separate treatment. 
$\left(2 \mathrm{a}^{* *}\right) \quad \mathrm{P} \rightarrow \mathrm{T}\left({ }^{\prime} \mathrm{P}\right.$ ')

$$
\left(2 \mathrm{~b}^{* *}\right) \sim \mathrm{P} \rightarrow \mathrm{T}\left({ }^{\circ} \sim \mathrm{P} ’\right)
$$

are incorrect, according to the multivalentist. For, if the left hand side of $\left(2 \mathrm{a}^{* *}\right)$ is neither T nor F, then this does not imply: ' $P$ ' is true. (Neither, of course, does it imply: ' $P$ ' is false). And similarly, since $\sim$ is a choice negation, if the left hand side of $\left(2 b^{* *}\right)$ is neither T nor F this does not imply: ' $\sim P$ ' is true. (Neither does it imply: ' $\sim P$ ' is false). T('P') is false when the left hand side of $\left(2 \mathrm{a}^{* *}\right)$ has value I; therefore, $\left(2 \mathrm{a}^{* *}\right)$ is not correct when $\mathrm{P}$ is indeterminate and so is not a universal truth about multivalued systems. This can be seen by truth table:

\begin{tabular}{c|cc}
$\mathrm{P}$ & $\mathrm{T}\left({ }^{\prime} \mathrm{P}\right.$ ') & $\mathrm{P} \rightarrow \mathrm{T}\left({ }^{\prime} \mathrm{P}\right.$ ') \\
\hline $\mathrm{T}$ & $\mathrm{T}$ & $\mathrm{T}$ \\
$\mathrm{I}$ & $\mathrm{F}$ & $? ?$ \\
$\mathrm{~F}$ & $\mathrm{~F}$ & $\mathrm{~T}$
\end{tabular}

Truth Table 4: The Offensive Direction of the Disquotational Principle

It is an open question as to what value should be put into the ?? location: possibly F since the consequent is 'more false' than the antecedent. But also possibly I. Either choice leads to a consistent three-valued logic; neither choice makes $\left(2 \mathrm{a}^{* *}\right)$ always take the value $\mathrm{T}$. $\left(2 \mathrm{a}^{* *}\right)$ is not a logical truth in any of these logics.

It should be emphasized that both directions of the biconditionals in both of (2a) and (2b) are required to make the DBA argument work. The implications $\left(2 a^{*}\right)$ and $\left(2 b^{*}\right)$ will not do the trick, at least in the argument as formulated. ${ }^{14}$ And this second objection to the

14 Here's a slightly different formulation that uses only the (**)-direction of the truth-schemas. The multivalentist will still find this argument wanting, since it involves the offensive $\left(2 \mathrm{a}^{* *}\right)$ and $(2 \mathrm{~b} * *)$.

$$
\begin{aligned}
& \text { 1. } \sim\left(\mathrm{T}\left({ }^{(} \mathrm{P} \text { ' }\right) \vee \mathrm{T}\left({ }^{\circ} \sim \mathrm{P}^{\prime}\right)\right) \\
& 2 \mathrm{a}^{* *} \quad \mathrm{P} \rightarrow \mathrm{T}\left({ }^{\prime} \mathrm{P}\right. \text { ') } \\
& 2 \mathrm{~b}^{* *} \quad \sim \mathrm{P} \rightarrow \mathrm{T}\left({ }^{\prime} \sim \mathrm{P}^{\prime}\right) \\
& \text { 3. } \sim \mathrm{T}\left({ } ^ { \circ } \mathrm { P } \text { ') } \& \sim \mathrm { T } \left({ }^{\circ} \sim \mathrm{P}\right.\right. \text { ') } \\
& \text { 4. } \sim \mathrm{T}\left({ }^{\prime} \mathrm{P} \text { ') } \rightarrow \sim \mathrm{P}\right. \\
& \text { 5. } \sim \mathrm{T}\left({ }^{\circ} \sim \mathrm{P} \text { ' }\right) \rightarrow \mathrm{P} \\
& \text { 6. } \sim \mathrm{P} \& \mathrm{P}
\end{aligned}
$$

The move from (1) to (3) is legitimate since only the classical values are involved and DeMorgan's Laws unquestionably hold for them. One might question, however, the use of contraposition in moving from $\left(2 \mathrm{a}^{* *}\right)$ to (4) and from $\left(2 \mathrm{~b}^{* *}\right)$ to (5). As we have said, if P has the value I, then T('P') is false, and there is then an issue as to whether the conditional $\left(2 \mathrm{a}^{* *}\right)$ is I or is F. Its contrapositive, (3), has a T antecedent and an I consequent in this case, and it is another choice as to whether this conditional is to be I or F. This choice is independent of the choice for the value of $\left(2 \mathrm{a}^{* *}\right)$, and if the choices are done differently then contraposition is not a valid rule of inference. (Nor would a rule of Modus Tollens be valid). 
DBA shows that these disquotational schemas are just wrong claims about multivalued logics that have choice negations. ${ }^{15}$

\section{Possible Replies}

We end with possible replies to our objections, in defence of the DBA, and our responses.

\section{A. Reply to Our Objection 1}

Williamson [1994: 193f] considers exclusion negation, calling it 'weak negation', and argues that it is not a plausible candidate for a logic of vagueness. He has two misgivings about exclusion negation: the first is that on intuitive grounds we want to say that the negation of a vague sentence is also vague. If the third value represents vagueness, then the negation of this third value should also have the third value, that is, the appropriate negation for vagueness is choice negation, not exclusion negation. Williamson's second argument revolves around the claim that exclusion negation cannot by itself account for 'higher order vagueness'. The idea is that first-order vagueness arises when it is thought that there are cases which are neither T nor F; second-order vagueness arises when it is thought that there are cases which are neither T nor 'weakly false'. And so exclusion negation cannot accommodate higher order vagueness unless still further types of negation are added to the language.

Possibly something can be made of this second argument, even though there is no value 'weakly false'. (Despite Williamson's assertion that this value is 'the metalinguistic analogue of weak negation', it can be seen from Truth Table 2 above that there is no such value.) On the other hand, this failure (if it is one) is not unique to exclusion negation. Even if we have choice ('strong') negation, one might think of second-order vagueness as arising when it is thought that there are cases which are neither T nor I, but 'somewhere in-between'. It seems to us that any finitely-many-valued logic — say with $n$ valueswill have a conceptual problem with higher order vagueness of order $(n-1)$. If one insists

15 As mentioned above, the disquotational principles might hold for the logic with exclusion negation, depending on how the biconditional is interpreted in the logic. In particular, the biconditional needs to be $\mathrm{T}$ when one side has the value I while the other side has the value $\mathrm{F}$.

Yet another variant on this argument form tries to prove directly that ( $\mathrm{T}\left({ }^{\prime} \mathrm{P}\right.$ ') $\vee \mathrm{F}\left({ }^{\prime} \mathrm{P}\right.$ ')), for any statement $\mathrm{P}$ - i.e., it tries to prove real bivalence. See Blum [2000: 301-2]. It starts with (1), which is true when $\sim$ is a choice negation.

$$
\begin{aligned}
& \text { 1. } \quad\left(\sim \mathrm { T } \left({ }^{\prime} \mathrm{P} \text { ') } \& \sim \mathrm{F}\left({ }^{\circ} \mathrm{P} \text { ') }\right) \rightarrow \sim \mathrm{T}\left({ }^{\circ} \sim \mathrm{P}^{\prime}\right)\right.\right. \\
& 2 \mathrm{a} * * . \quad \mathrm{P} \rightarrow \mathrm{T}\left({ }^{\prime} \mathrm{P}\right. \text { ') } \\
& 2 \mathrm{~b}^{* *} . \quad \sim \mathrm{P} \rightarrow \mathrm{T} \text { (' } \sim \mathrm{P} \text { ') } \\
& \text { 3. } \quad \mathrm{T}\left({ }^{\circ} \sim \mathrm{P}^{\prime}\right) \rightarrow\left(\mathrm{T}\left({ }^{(} \mathrm{P}{ }^{\prime}\right) \vee \mathrm{F}\left({ }^{(} \mathrm{P} \text { ') }\right) \quad\right. \text {-from 1, contraposition and DeMorgan's Law } \\
& \text { 4. } \quad \sim \mathrm{P} \rightarrow\left(\mathrm{T}\left({ }^{(} \mathrm{P} \text { ') }\right) \vee \mathrm{F}\left({ }^{(} \mathrm{P} \text { ') }\right) \quad \text {-from } 2 \mathrm{~b}^{* *}, 3 \text {, transitivity of } \rightarrow\right. \\
& \text { 5. } \quad \mathrm{P} \rightarrow\left(\mathrm { T } \left({ }^{\prime} \mathrm{P} \text { ') } \vee \mathrm{F}\left({ }^{(} \mathrm{P} \text { ') }\right) \quad\right.\right. \text {-from 2, add disjunct to consequent } \\
& \text { 6. (T('P') } \left.\vee F\left({ }^{\prime} \mathrm{P}^{\prime}\right)\right) \text {-from } 4,5 \text { by separation of cases }
\end{aligned}
$$

We will not ponder whether contraposition, transitivity and this version of separation of cases are valid in our three-valued logic. We content ourselves in pointing out that this argument also relies on the incorrect $\left(2 a^{* *}\right)$ and $\left(2 b^{* *}\right)$. 
on $(n-1)$-order vagueness, then one requires $(n+1)$ values to handle it (at least, if one wants to assign each order of vagueness to a different truth value). So the fact that exclusion negation is not well-suited to higher-order vagueness does not seem a particularly salient criticism of its use in deflecting the force of the DBA argument.

In any case, the DBA argument as considered here is directed to demonstrating that denying bivalence is absurd. Williamson's considerations concerning exclusion negation, assuming there is any correctness in them, show at most that if one has certain connectives in a multivalent language, then there might be complex difficulties ahead. This seems not particularly relevant to the issue at hand, viz., whether denying bivalence is absurdrather than, say, more technically tricky than classical logic.

\section{B. Replies to Our Objection 2}

The multivalentist claims to have shown that the disquotational schemas are simply wrong. In which case, they cannot be successfully deployed, in the DBA argument, to show that denying bivalence is absurd. ${ }^{16}$ What might a defender of the DBA argument say in response?

We will here discuss two possible replies. The first is a direct defence of (2a), repeated below:

(2a) $\mathrm{T}\left({ }^{\prime} \mathrm{P}\right.$ ') $\leftrightarrow \mathrm{P}$

Rather than responding to our specific complaints, this first defence tries to show that (2a) simply must be true. Here's what Williamson [1996: 269, italics added] says about (2a). Having argued that 'TW is thin' is meaningful, he writes:

Once we are permitted to use 'thin', we can argue that 'TW is thin' says something that would have been true in various circumstances, because I would have been thin. Then " "TW is thin" is true if and only if TW is thin' says something too. But if it says anything, it is true. For, given that 'TW is thin' means that TW is thin, what more could it take for ' $T W$ is thin' to be true than for $T W$ to be thin?

This little argument justifies the conclusion 'if it says anything, it is true' by the rhetorical 'what more could it take for "TW is thin" to be true ...?'

The second reply we will consider is a more indirect defence of (2a); its most immediate aim is to head off one aspect of our attack, our claims about $\left(2 \mathrm{a}^{* *}\right)$. We called $\left(2 \mathrm{a}^{* *}\right)$, the right-to-left part of $(2 \mathrm{a})$, into question by providing Truth Table 4 , in which this conditional did not come out as a logical truth (under either of the interpretations we offered). The second reply, on behalf of the DBA argument, questions the coherence of that truth table. In particular, it questions what it can mean to assign I to $\mathrm{P}$, in the middle row.

16 Williamson [1996: 268] says, in a footnote, 'without a disquotational schema, it is doubtful that one has a truth predicate at all'. Perhaps, but it needn't be of the sort he employs in the DBA argument. There are other ways to state disquotational schemas for multivalued logics. As mentioned in the text, the ones given by Williamson are appropriate only for those two-valued logics that have enough of classical negation to support some (possibly extended) versions of the Law of Excluded Middle and equivalence of double negations. Logics that differ in any of these ways will employ different disquotational schemas. 
Our strategy will be to discuss Williamson's rhetorical question first. That will overcome the direct reply on behalf of (2a). Doing so will also provide us with some tools necessary for addressing the challenge to the coherence of Truth Table 4 .

So, what more can it take for 'TW is thin' to be true, beyond TW being thin? Well, recall the kind of case that the multivalentist (whether a multivalentist due to vagueness or otherwise) appeals to. These are cases such that in some contexts an utterance of ' $\mathrm{P}$ ' is true, in others an utterance of ' $\mathrm{P}$ ' is false, and in still others, a factor metaphysically relevant to whether an utterance of ' $\mathrm{P}$ ' is true or false is simply lacking. Different philosophical authors have suggested different such 'factors' [Searle 1980; Sperber and Wilson 1986; Travis 1985]. The 'factors' - to put a dignified label on what is surely a mixed-up amalgam of who-knows-what - include relevant contrast class, and the purposes of the participants, among many other things. We won't here take a stand on whether such views are ultimately plausible. Our point is merely that there are coherent accounts like this, and that one can presumably deploy any such account to make sense of a situation in which $\mathrm{P}$ does obtain, here and now, yet it would be incorrect to say, of the sentence ' $\mathrm{P}$ ', that it was true tout court.

To answer Williamson's rhetorical challenge with regard to vagueness, it remains only to make it coherent that sentences containing vague expressions - including 'thin'—are such that they too belong in the class of sentences that exhibit indeterminacy due to a special kind of context sensitivity. But by the very nature of the multivalentist's case, TW might be thin, given the prevailing standards, the salient contrast class, the purposes at hand, other things about the speaker's intentions, etc., without the sentence type 'TW is thin' thereby becoming just plain true. The multivalentist about vagueness is free to think that utterances predicating thinness (tallness, youth, etc.) are true only relative to .... Thus we can have a particular situation in which an utterance of 'TW is thin' is true (because of the purposes actually in play, the actually salient comparison class, etc.) yet the multivalentist may still, quite coherently, be unwilling to accept (5):

(5) 'TW is thin' is true

To be clear, we aren't making a point about indexicals, demonstratives, or other familiar context sensitive items in sentences. To allow for explicit indexicals, and demonstratives (and tense), one might take 'is true' to apply correctly only when, having relativized all of the expression's context sensitive elements of structure accordingly, the result is a relativized sentence that is true tout court. Even taking 'is true' that way, the sentence 'That was tall' will still be non-true if - as the multivalentist is free to insist-it is utterances of that sentence that are true or false, relative to something more than what the context sensitive slots (in the present case, 'that' and tense) allow for. Though there may be exceptions - e.g., 'If there are three thin tadpoles in Germany then there are more than two thin tadpoles in Germany'-sentence types that contain vague expressions are typically not true, or false, not even relative to some fixed set of parameters, the way some other sentence types containing tense markers and indexicals can be true/false. (Instead, vague sentence types receive the value I.)

How can this be, given that utterances of such sentences can be true/false? Well, what makes utterances of such sentences true is too unconstrained, variable, and 'holistic' to be captured by a 'parameter'. Hence it won't do to talk of the sentence type being true/false relative to such a parameter. Put in terms of the familiar jargon, while one might hope that 
'I' and 'now' have a Kaplan-style character, with each word standing for a genuine function from some fixed set of elements to an extension, vague terms like 'tall', 'young', 'heap', and so on, do not have any such character. What determines the extension of utterances of them cannot be modelled in Kaplan's clean way [1989]. Or so it could be coherently claimed. (Why not have the sentence type be true/false relative to the whole shebang, i.e., 'context' in the broadest sense? Because of a preservationist hope for logic, shared by both bivalentists and their opponents, which will shortly emerge, in our brief remarks about Strawson.)

Here is another way of distinguishing familiar indexicals from the new kind of context sensitivity being suggested here. The multivalentist can say, about the sentence 'TW is thin', that it lacks a truth-value not in the way 'That is mine' does, but rather more in the way that 'John will', 'John isn't strong enough', or 'John knows' do. None of these latter three sentences is true or false tout court. Not even after fixing values for context-sensitive elements in syntax. Though each can be used to assert a complete truth-value-bearing proposition, context must, in each case, do more than provide referents for context sensitive slots in the sentences for a true/false proposition to be derived: in the first case, the context must determine what John will do; in the second case, it must determine what goal John isn't strong enough to achieve; in the last case, it must determine which proposition is being discussed, not to mention what degree of justification is required for knowledge in the case at hand. (Having introduced this second kind of context sensitive sentence, note how non-compelling the following rhetorical question is: 'What more could it take for the sentence "John isn't strong enough" to be true than that John isn't strong enough?' The point is that nothing will make the sentence type 'John isn't strong enough' true, even given a set of parameters for explicit indexicals/tense/etc. See Bach [1994] for discussion.)

A more radical view, of course, is that no sentence type is true or false, even relative to reference assignments to explicitly context-sensitive items; sentence types, goes this line of thought, just aren't the right kind of thing to exhibit truth/falsehood. Instead, it is statements and other speech acts that have truth values. (Compare: no sentence type is a lie, even 'relative to a context', because sentence types aren't the right kind of thing to be lies.) This way of seeing things would, of course, allow one to reject (2a) and (2b). But, as Strawson [1950] saw clearly, it would at the same time call into question the whole idea of a logic for natural language sentence types - whether bivalent or multivalent. Best, then, to stick with the more moderate idea that only some sentences-including sentences containing vague expressions - do not express truths/falsehoods, even after all context sensitive elements of structure are assigned reference. Goes this line of thought, if we want our logic to apply to indicative sentence types generally, and not just to sentences that are true/false after reference assignment to indexicals and such, we need to have more than two truth values. Importantly, one isn't, in allowing for sentences of this new kind, giving up the very idea of a logic for sentence types - which would fly in the face of our presenting a possible multivalent logic at all. The foregoing is a preservation-by-modification strategy, not an attempt to abandon the whole project-which is quite different from the more radical Strawsonian idea, that there is no exact logic for English (and other natural language) sentences.

We can sum up our response to this 'direct defence' of (2a) as follows. Look again at the quotation from Williamson above. His first sentence just assumes that the sentence 
type 'TW is thin' says something that would have been true in various circumstances. Crucially, this is not merely the (perfectly plausible) assumption that utterances of 'TW is thin' can be true or false, nor is it merely the (undeniable) assumption that a speaker of 'TW is thin' can make a true or false statement. No, it is the much more controversial assumption that this sentence type is of the sort that says something true or false. Or anyway, it, the sentence type, says something true once all of the explicitly contextsensitive 'slots' are assigned their referents. But this assumption is one that the multivalentist is quite free to reject, since she is welcome to think that the content of the sentence type 'TW is thin', containing as it does a vague word, determines not a true or false proposition, but something sub-propositional - something that can only be evaluated for truth/falsity given some extra 'factors' (beyond reference assignment to indexicals) like speakers' purposes, contrast classes, or whatever. Saying this, she can thereby drive a wedge between $\mathrm{P}$ obtaining in a particular circumstance - given the actual purposes of the speakers, the salient comparison classes, etc.- - and the sentence type ' $\mathrm{P}$ ' being true, tout court. And then, given such a coherent difference, she can without absurdity reject the disquotational clauses used in DBA.

We say again: we are not claiming that this way of avoiding bivalence-i.e., by means of positing sentences that exhibit a special kind of context sensitivity-faces no challenges. In particular, we are aware that inventive means have been proposed for taming this (apparently) new kind of context sensitivity, to make it logic-friendly. (See for example Stanley [2000; 2002]). Truth be told, we are not sanguine about such attempts at taming context-sensitivity due to vagueness. Still, our point in the present paper is a more modest one, viz., that denying bivalence still ends up being coherent, given that this commitment to a quite distinct variety of context sensitivity is not patently absurd.

The first reply to our objection 2 took the form of a rhetorical question, viz. what more could it take for 'TW is thin' to be true than for TW to be thin? Failure to answer would seemingly leave $\left(2 \mathrm{a}^{* *}\right)$ intact. Happily, we provided an answer above. The second reply to our objection 2 is, as noted, aimed more specifically at the details of our attack on $\left(2 \mathrm{a}^{* *}\right)$. Recall that we employed Truth Table 4 to show that $\mathrm{P} \rightarrow \mathrm{T}($ ' $\mathrm{P}$ ') is not correct in multi-valued systems. The key point was that, when $\mathrm{P}$ is assigned $\mathrm{I}$, the consequent is more false than the antecedent-hence the whole conditional is non-true. Given that this was our argument against (2a), one can indirectly defend (2a) by raising problems for our truth table. As follows. It's reasonable to wonder what this third value is that is being assigned to $\mathrm{P}$, in the middle row of Truth Table 4. It is easy enough to put a label on the intermediate value, namely indeterminate. But what does this mean? Patently, being indeterminate cannot merely amount to our not being able to tell whether $\mathrm{P}$ is true or false, for this would collapse the (supposedly) non-bivalent view back into Williamson's own epistemic view.

It seems to us that the multivalentist has two immediate and compelling replies to this indirect defence of (2a). First, it cannot just be assumed that there is no third value I: that would beg the question against the multivalentist. Granted, looking at things in a bivalent frame of mind, such that reality is a matter of possession or absence of a property, it's hard to see a place for a third value. But, patently, that's not the right frame of mind to adopt when assessing the DBA. The DBA is supposed to establish bivalence, not presuppose it. Second, even if one agrees for the sake of argument to excise indeterminacies 'in the world' as it were, there would nevertheless be a coherent, non-epistemic, notion of 
indeterminacy for linguistic items. So even without indeterminacies 'in the world', we can give a coherent content to I. Precisely this became clear in our discussion of Williamson's rhetorical question: given the new kind of context sensitivity discussed above, one cannot move quite so quickly from facts obtaining in the world, here and now, to linguistic items being true. (It is precisely this quick move, of course, which lies at the very heart of $\left(2 \mathrm{a}^{* *}\right)$.)

It may clarify things if we say explicitly how the reply to Williamson's rhetorical question allows one also to defend the coherence of the middle row of Truth Table 4. That is, to say explicitly how our rebuttals to the direct and indirect replies on behalf of (2a) relate. This relationship is non-obvious because, while the burden of the former discussion was to separate $\mathrm{P}$ obtaining here and now from ' $\mathrm{P}$ ' being true, the current concern is prima facie quite different, namely to make room for $\mathrm{P}$ being indeterminate in a non-epistemic way. In fact, however, these two issues are connected.

Taking Truth Table 4 to relate, schematically, the sentence type $\mathrm{P}$ to the more complex sentence type $\mathrm{T}$ ('P'), we can say, given our discussion above, that there are three kinds of sentence types that can substitute for $\mathrm{P}$ :

(a) sentence types that either are true tout court or are true relative to the relevant specification of referents for context-sensitive items;

(b) sentence types that either are false tout court or are false relative to the relevant specification of referents for context-sensitive items;

(c) sentence types that aren't true or false, even given the relevant specification for context-sensitive items - vague sentences being a sub-case - and such that no logic-friendly set of parameters will allow relativization in these cases.

The first row of Truth Table 4 applies in case (a), and the third row applies in case (b). Given the new kind of context sensitivity introduced above, however, the middle row is required as well, to handle cases of kind (c). It is this third kind of case which then shows, in the Truth Table, that $\left(2 \mathrm{a}^{* *}\right)$ is not a logical truth. ${ }^{17}$

Our conclusion, then, is that the multivalentist position is completely coherent, at least from a logical point of view. That is to say, the conclusion drawn by some holders of the DBA argument, that denying bivalence leads clearly and immediately to a logical contradiction even by the lights of the multivalentist herself, is simply wrong. On the other hand, the DBA might indeed show that many complex changes to classical logic, including new disquotational schemas, are required to uphold a multivalued approach to vagueness. And perhaps this 'does not integrate as well with theories in other domains' as does classical logic. But, as noted at the outset, that's a different story altogether.

University of Alberta

Carleton University

Received: October 2002

17 One can say something similar to this even if one takes truth tables to relate utterances. The three kinds of utterances would be: true ones, false ones, and ones which were made without a metaphysically requisite 'factor' being in place. It is utterances of this last kind which receive the value I. 


\section{REFERENCES}

Bach, K. 1994. Conversational Implicature, Mind and Language 9: 124-62.

Blum, A. 2000. Truth-Values, Iyyun 49: 301-2.

Cargile, J. 1969. The Sorites Paradox, British Journal for the Philosophy of Science 20: 193-202.

Kaplan, D. 1989. Demonstratives, in Themes from Kaplan, ed. J. Almog, J. Perry, and H. Wettstein, New York: Oxford University Press: 481-564.

Searle, J. 1980. The Background of Meaning, in Speech Act Theory and Pragmatics, ed. J. Searle, F. Kiefer, and M. Bierwisch, Dordrecht: Reidel: 221-32.

Sperber, D. and D. Wilson 1986. Relevance, Cambridge MA: Harvard University Press.

Stanley, J. 2000. Context and Logical Form, Linguistics and Philosophy 23: 391-434.

Stanley, J. 2002. Nominal Restriction, in Logical Form and Language, ed. G. Preyer \& G. Peter, Oxford: Clarendon Press: 365-88.

Strawson, P. 1950. On Referring, Mind 59: 320-44.

Travis, C. 1985. On What Is Strictly Speaking True, Canadian Journal of Philosophy 15: 187-229.

Williamson, T. 1996 (1992). Vagueness and Ignorance, in Vagueness: A Reader, ed. R. Keefe and P. Smith, Cambridge MA: MIT Press: 265-80.

Williamson, T. 1994. Vagueness, London and New York: Routledge. 